\title{
Chimeric Protein PSPF, a Potential Vaccine for Prevention Streptococcus pneumoniae Infection
}

\author{
Suvorov $\mathbf{A}^{1,2^{*}}$, Dukhovlinov $\mathbf{I}^{1,3}$, Leontieva $\mathbf{G}^{1}$, Kramskaya $\mathrm{T}^{1}$, Koroleva $\mathbf{I}^{1}$, Grabovskaya $\mathrm{K}^{1}$, Fedorova $\mathrm{E}^{1,3}$, Chernyaeva $\mathrm{E}^{1}$, Klimov $\mathbf{N}^{1,4}$, Orlov $\mathbf{A}^{1,4}$ and Uversky \\ $\mathbf{V}^{5}$ \\ ${ }^{1}$ Federal State Budgetary Scientific Institution "Institute of Experimental Medicine", 12, Academic Pavlov Street, Saint-Petersburg, 197376, Russia \\ ${ }^{2}$ Saint-Petersburg State University, 7-9, University Embankment, Saint-Petersburg, 199034, Russia \\ ${ }^{3}$ The limited liability company "Epitop", 22-4, Lesnoi Avenue, Saint-Petersburg 194044, Russia \\ ${ }^{4}$ The limited liability company "Universal Biosystems", 88-8, Leninsky Avenue Saint-Petersburg 198332, Russia \\ ${ }^{5}$ University of South Florida College of Medicine Department of Molecular Medicine, 12901 Bruce B. Downs BIvd, MDC07 Tampa, FL 33612, USA
}

*Corresponding Author: Alexander Suvorov, Head of molecular microbiology division of Federal, State Budgetary Scientific Institution "Institute of Experimental Medicine", Academic Pavlov Street, St. Petersburg, Russia; Tel: +79219342812; E-mail: Alexander_suvorov1@hotmail.com

Received date: Nov 01, 2015; Accepted date: Dec 18, 2015; Published date: Dec 21, 2015

Copyright: ( 2015 Suvorov A, et al. This is an open-access article distributed under the terms of the Creative Commons Attribution License, which permits unrestricted use, distribution, and reproduction in any medium, provided the original author and source are credited.

\begin{abstract}
A chimeric protein, designated PSPF (Pneumococcus Surface Proteins and Flagellin) was constructed from conservative and immunogenic fragments of $S$. pneumoniae surface proteins PspA, Spr1875, PsaA and the Salmonella typhiurium flagellin terminal domains FliC1, Flic2 functioning as adjuvant. PSPF was highly immunogenic in mice and induced protection from virulent $S$. pneumonia strains. All the subtypes of $S$. pneumoniae under study were recognized by anti-PSPF sera. Thus, the chimeric recombinant PSPF protein is a promising vaccine candidate for immunization of humans against $S$. pneumoniae.
\end{abstract}

Keywords: Pneumonia; Streptococcus pneumonia; Chimeric protein; Recombinant vaccine; TLR-5; Flagellin

\section{Introduction}

According to WHO data, Streptococcus pneumoniae is among the most common bacterial infections responsible for mortality among children in developing countries $[1,2]$. S. pneumoniae is also the most often cause of bacterial pneumonia, meningitis, bacteremia, bronchitis, sinusitis and otitis media. In Europe and the US, the annual incidence of invasive pneumococcal disease ranges from 10 to 100 cases per 100000 of the population [1]. S. pneumoniae isolates are covered by a thick polysaccharide capsule, which provides protection against opsonization and phagocytosis. Pneumococcal capsule polysaccharides (PSs) are the first surface elements recognized by an immune system and characterized by high antigenic variability. At present $91 S$. pneumoniae serotypes have been discovered and the number is constantly growing [3]. The increasing frequency of the pneumococcal isolates resistant to commonly used antibiotics complicates control of pneumococcal infections [4-6]. Current pneumococcal vaccines are all based on PSs antigens. Therefore, the effect of a polysaccharide-based vaccine is restricted to the PS serotypes included in the vaccine, and the coverage varies due to different geographical serotype distributions [7]. Another disadvantage of PS vaccines are based on the weak immunological memory [8]. In this respect, surface proteins of $S$. pneumoniae which are also exposed and may be reached by the opsonising antibodies are advantageous vaccine candidates due to the smaller degree of variability and higher immunogenicity.

The goal of the work was to study immunogenicity and preventive effect of chimeric protein, composed of the fragments of three surface proteins of $S$. pneumoniae. The choice of conservative and immunogenic fragments of surface proteins PsaA, PspA and Spr1875 to include in the chimeric vaccine was based on previous studies, which reported their ability to induce protective antibodies [9-13]. PsaA is a highly conservative lipoprotein expressed by several serotypes and essential for virulence of $S$. pneumoniae [9]. PspA (Pneumococcal surface protein A) is a surface protein known to contribute to $S$. pneumonia virulence by binding human lactoferrin and by impeding complement activation in vivo and in vitro [10,11]. The surface protein Spr1875 (also known as LysM domain-containing protein) exhibits immunogenic properties and contributes to $S$. pneumoniae virulence due to its role in the development of pneumococcal meningitis [12,13].

Salmonella typhiurium flagelin FliC N- and C-terminal fragments known to interact with Toll-like receptor-5 (TLR-5) were included into the vaccine molecule as an activator of innate and adaptive immune responses $[14,15]$. All these components assembled in one molecule were expressed in E.coli system, isolated and tested for immunogenicity and the ability to provide the appearance of protective IgG.

\section{Materials and Methods}

\section{Modeling the recombinant chimeric protein, artificial gene and expression plasmid}

Amino acid sequence of chimeric protein based on PspA, Spr1875, PsaA and FliC fragments, separated with appropriate flexible bridges (called PSPF) was designed in silico according to the previously accumulated knowledge of the immunogenic domains and putative three dimensional structures. Nucleotide sequence of the chimeric protein was optimized for expression in E. coli (Figures 1,2). Synthesis of nucleotide sequence of PSPF was performed by elongation of the overlapping oligonucleotides [16]. The synthetic chimeric gene was 
Citation: Suvorov A, Dukhovlinov I, Leontieva G, Kramskaya T, Koroleva I, et al. (2015) Chimeric Protein PSPF, a Potential Vaccine for Prevention Streptococcus pneumoniae Infection. J Vaccines Vaccin 6: 304. doi: 10.4172/2157-7560.1000304

Page 2 of 8

cloned in pET24b+ vector (Invitrogen), producing the expression plasmid pPSPF, which was transformed into E. coli BL21 (Invitrogen). The gene encoding for chimeric protein devoid of S.typhimurium flagellin fragments (PSP) was inserted into pET25b+ giving expression plasmid pPSP, which was also transformed into E. coli BL21(DE3).

\section{Artificial protein structure prediction}

The sequence of the designed artificial protein PSPF was virtually cut into domains and the 3D structures of these domains were found in public databases or $a b$ initio. The final refinement of the overall 3D structure was performed employing I-Trasser algorithm [17]. The reliability of the structure prediction by I-Trasser is $70 \%$. Prediction of intrinsic disorder and disorder-based binding sites of the designed artificial protein PSPF and its parent proteins were evaluated by several predictors of the PONDR family, such as PONDR ${ }^{\circ}$ VLXT [18], PONDR $^{\circ}$ VSL2 [19], PONDR ${ }^{\circ}$ VL3 [20], and PONDR ${ }^{\circ}$ FIT [21]. Disorder-based binding sites in the PSPF protein were identified by the ANCHOR algorithm [22].

\section{Chimeric proteins expression and purification}

Recombinant E.coli with plasmids encoding for PSPF and PSP were grown in PYP5052 medium containing $0.2 \%$ lactose according to Studier's method [23]. The proteins PSPF and PSP were extracted from

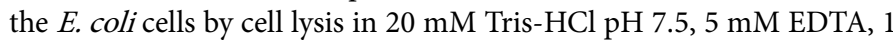
$\mathrm{mM}$ PMSF and sonication (7 rounds of $30 \mathrm{sec}$ pulses with $30 \mathrm{sec}$ pauses, ultrasound frequency $22 \mathrm{kHz}$ ). Bacterial lysates were centrifuged and the pellets were suspended in $1 \mathrm{M}$ urea. After the next centrifugation the pellets were suspended in $2 \mathrm{M}$ urea and centrifuged again. The pellets were dissolved in $20 \mathrm{mM}$ Na-phosphate buffer, with $0.5 \mathrm{M} \mathrm{NaCl}, 6 \mathrm{M}$ guanidine- $\mathrm{HCl}, \mathrm{pH} 8.0$ and subjected to Ni-NTA (Invitrogen) purification chromatography according to producer's protocol. After final dialysis against $20 \mathrm{mM}$ tris- $\mathrm{HCl} \mathrm{pH} 7.5,5 \mathrm{mM}$ EDTA and $1 \mathrm{mM}$ PMSF the obtained products contained the chimeric proteins PSPF and PSP with purity of $97 \%$ and concentration $1 \mathrm{mg} / \mathrm{ml}$ with LPS concentration not exceeding $0.016 \mathrm{EU} / \mathrm{mg}$ evaluated by Endosafe LAL assay (Charles River).

\begin{tabular}{|l|l|l|}
\hline Number & Collection number & Serotype \\
\hline 1 & ATCC BAA-1667 $^{-}$ & 6 \\
\hline 2 & ATCC $^{\circledR} 6319^{\text {TM }}$ & 19 \\
\hline 3 & 442 & $19 \mathrm{~F}$ \\
\hline 4 & 68 & $6 \mathrm{ABC}$ \\
\hline 5 & 16 & $9 \mathrm{VA}$ \\
\hline 6 & 133 & $19 \mathrm{~A}$ \\
\hline 7 & 73 & 3 \\
\hline 8 & 1734 & 34 \\
\hline 9 & 88 & 8 \\
\hline 10 & 78 & 14 \\
\hline 11 & 835 & $9 \mathrm{LN}$ \\
\hline
\end{tabular}

Table 1: Streptococcus pneumonia strains used in the study.

\section{S. pneumoniae strains}

S. pneumoniae clinical isolates were obtained from the collection of the Research Institute of Pediatric Infections (St. Petersburg, Russia) and two strains were purchased from ATCC (ATCC $6319^{\circ}$ type 19, ATCC BAA-1667-type 6) (Table 1). Pneumococci were cultured in anaerobic conditions at $37^{\circ} \mathrm{C}$ for 18 hours in THB medium with $20 \%$ horse serum (Difco). Schaedler agar with sheep red blood cells was used as a solid medium.

\section{Animals}

The study was performed using BALB/c inbred mice (female, 8 weeks old, 18-20 g) obtained from «Pushino» nursery. All animals were housed in illuminated and temperature controlled conditions. Mice were offered standard commercial feed and water ad libidum and treated according to the Guide for the Care and Use of laboratory animals of the Institute of Experimental Medicine.

\section{The experimental design}

The animal study of vaccine described in Tables 2-3. In short, three groups of animals were injected with three different dosages of vaccine. Two groups used as controls: the reference vaccine group and a group of mice received placebo.

\begin{tabular}{|c|c|c|c|c|c|}
\hline Immunogen & $\begin{array}{l}\text { Group } \\
\mathbf{s}\end{array}$ & $\begin{array}{l}\text { The first } \\
\text { immuni- } \\
\text { zation } \\
\text { dose }\end{array}$ & $\begin{array}{l}\text { The } \\
\text { second } \\
\text { immuni- } \\
\text { zation } \\
\text { dose }\end{array}$ & $\begin{array}{l}\text { The mode of } \\
\text { S. pneumoniae } \\
\text { infection }\end{array}$ & $\begin{array}{l}\text { Number } \\
\text { of } \\
\text { animals }\end{array}$ \\
\hline \multirow{6}{*}{$\begin{array}{l}\text { PSPF } \\
\text { adjuvant }\end{array}$} & \multirow{2}{*}{1} & \multirow{2}{*}{$5 \mu \mathrm{g} /$ mouse } & \multirow{2}{*}{$\begin{array}{l}2,5 \mu \mathrm{g} / \\
\text { mouse }\end{array}$} & intraperitoneally & 10 \\
\hline & & & & intranasally & 10 \\
\hline & \multirow{2}{*}{2} & \multirow{2}{*}{$\operatorname{lu}_{\text {mouse }} \mu \mathrm{g} /$} & \multirow{2}{*}{$\begin{array}{l}5 \\
\text { mouse }\end{array}$} & intraperitoneally & 10 \\
\hline & & & & intranasally & 10 \\
\hline & \multirow{2}{*}{3} & \multirow{2}{*}{$\begin{array}{l}20 \\
\text { mouse }\end{array}$} & \multirow{2}{*}{$\operatorname{mouse}_{\text {mog }} \mu \mathrm{g} /$} & intraperitoneally & 10 \\
\hline & & & & intranasally & 10 \\
\hline \multirow{2}{*}{$\begin{array}{l}\text { Adjuvant } \\
\text { only }\end{array}$} & \multirow{2}{*}{4} & \multirow{2}{*}{\multicolumn{2}{|c|}{ No PSPF (control group) }} & intraperitoneally & 10 \\
\hline & & & & intranasally & 10 \\
\hline \multirow{2}{*}{$\begin{array}{l}\text { Reference } \\
\text { vaccine }\end{array}$} & \multirow{2}{*}{5} & \multirow{2}{*}{$\begin{array}{ll}1 & \text { vial/8 } \\
\text { mice } & \end{array}$} & \multirow{2}{*}{$\begin{array}{l}1 \text { vial } \\
\text { mice }\end{array}$} & intraperitoneally & 10 \\
\hline & & & & intranasally & 10 \\
\hline
\end{tabular}

Table 2: Scheme of immunization.

\section{Reference vaccine}

Human pneumococcal conjugate vaccine (Prevnar 7) containing 2 $\mu \mathrm{g}$ of each polysaccharide of $4,6 \mathrm{~B}, 9 \mathrm{~V}, 14,18 \mathrm{C}, 19 \mathrm{~F}, 23 \mathrm{~F}$ serotypes and 20 micrograms of carrier protein CRM197 per dose was used as reference vaccine.

\section{The route of administration}

Chimeric proteins PSPF and PSP and reference vaccine were administered subcutaneously. Each injection of chimeric proteins contained $0.1 \mathrm{ml}$ of the adjuvant Imject Alum (Thermo Scientific) and $0.1 \mathrm{ml}$ of the protein solution in PBS buffer. A placebo group of mice 
were injected with $0.1 \mathrm{ml}$ of PBS and $0.1 \mathrm{ml}$ of adjuvant. A reference vaccine group immunized with Prevnar 7 in proportion 1 human dose per 8 mice.

\begin{tabular}{|l|l|}
\hline Day & Action \\
\hline Day 0 & $\begin{array}{l}\text { The first vaccination: groups 1-3, 5 } \\
\text { Adjuvant injection in control group: group 4 }\end{array}$ \\
\hline Day 21 & $\begin{array}{l}\text { Taking the blood from mice to identify specific antibodies (IgG) } \\
\text { titer }\end{array}$ \\
\hline Day 22 & $\begin{array}{l}\text { The second vaccination (1/20f the first vaccination dose): groups } \\
1-3,5 \text { Adjuvant injection in control group: group 4 }\end{array}$ \\
\hline Day 35 & $\begin{array}{l}\text { Taking the blood from mice to identify specific antibodies (IgG) } \\
\text { titer }\end{array}$ \\
\hline Day 42 & $\begin{array}{l}\text { Taking the blood from mice to identify specific antibodies (IgG) } \\
\text { titer }\end{array}$ \\
\hline Day 49 & $\begin{array}{l}\text { Taking the blood from mice to identify specific antibodies (IgG) } \\
\text { titer }\end{array}$ \\
\hline Day 50 & Intranasal infection with S.pneumoniae strain 73 serotype 3 \\
\hline Day 53 & $\begin{array}{l}\text { Intraperitoneal infection with S.pneumoniae strain 442 serotype } \\
19 F\end{array}$ \\
\hline Days 54-63 & Monitoring of the animals survival \\
\hline
\end{tabular}

Table 3: Schedule of immunization.

\section{Serum IgG titer detection}

Blood was collected from submaxillary vein. Specific IgG levels were determined by ELISA in 96-well ELISA plates (Nunc) coated overnight at $4^{\circ} \mathrm{C}$ with the PSP or PSPF proteins. The diluted sample $(100 \mu \mathrm{l})$ was added to duplicate wells and incubated $1 \mathrm{~h}$ at $37^{\circ} \mathrm{C}$. HRP-labeled goat anti-mouse IgG antibodies (Sigma) diluted in blocking buffer were added $(100 \mu \mathrm{l} /$ well). After incubation at room temperature for $1 \mathrm{hr}$, plates were developed with TMB substrate (BD Bioscience) according to the manufacturer's instructions. ELISA endpoint titers were defined as inverse value of the highest dilution that yielded an OD value above 2 times the mean of negative control wells.

\section{Interaction of PSPF- specific sera with different $S$. pneumoniae serotypes}

The study was performed using dot -blot assay on nitrocellulose membranes. Daily cultures of $S$. pneumoniae were washed in PBS and three microliters of each bacterial suspension were applied to nitrocellulose membranes and dried. The membrane was incubated in blocking buffer (5\% dry milk dissolved in PBS pH 7.4). After the incubation, membrane was treated with mice sera containing PSPFspecific antibodies with titer 1:400000 diluted 1000 times in blocking buffer. Membrane was placed in a conjugate solution (anti-mouse IgG (Fc-specific)-peroxidase). Color was developed in ready to use TMB Liquid Substrate System for Membranes (Sigma) for 3-5 minutes.

\section{Estimation of $S$. pneumoniae lethal doses}

Bacterial aliquots of $S$. pneumoniae were inoculated into mice by intraperitoneal or intranasal administration. Survival level was monitored for 10 days. The minimum bacterial doses which caused the death of the 50 or $100 \%$ of the animals were evaluated as $\mathrm{LD}_{50}$ or $\mathrm{LD}_{100}$.

\section{Protective efficacy of recombinant vaccine}

Ten $S$. pneumoniae strains belonging to ten different serotypes were analyzed (Table 1). Only two of these, strain 442 (serotype 19F) and strain 73 (serotype 3) were highly virulent for the mice and were used to investigate the vaccination effectiveness in lethal models of pneumococcal infection. All bacterial strains were tested for recognitions by PSPF-specific IgG antibodies in dot-blot ELISA.

Vaccinated and controlled mice were infected with virulent strains by intraperitoneal or intranasal administration on the $50^{\text {th }}$ day after the first immunization. Intraperitoneal infection was induced with $\mathrm{LD}_{100}$ of the strain 442 (serotype 19F). One infective dose contained $3 \times 10^{2}$ $\mathrm{CFU}$ of the pathogen. Intranasal infection was induced with LD50 of the strain 73 (serotype 3). One infectious dose contained $1 \times 10^{7} \mathrm{CFU}$ of the pathogen. Each experimental group included 8-10 mice.

\section{Statistics and Data Handling}

Data analysis included the estimation of the medium values and the standard deviation $(M \pm \sigma)$. Statistical relevance was estimated employing t-test by Student or U-test by Mann- Whitney. Differences were considered significant at $\mathrm{p}<0.05$.

The survival curves of mice were compared for significance using the log-rank test. Differences were considered significant at $\mathrm{p}<0.05$

\section{Results}

\section{Molecular design of artificial chimeric protein PSPF}

Developed chimeric recombinant protein PSPF contains the fragments of $S$. pneumonia proteins PspA, PsaA, Spr1875 and $S$. typhimurium flagellin FliC. PspA is a surface protein showing high heterogeneity between pneumococcal strains [24]. In $S$. pneumonia PspA varies in size from 439 to 649 amino acids and contains three major domains: the $\mathrm{N}$-terminal 288 amino acid functional helical domain, 82 amino acid flexible proline-rich segments, and the Cterminal choline-binding domain responsible for cell wall binding. Protective Mabs against PspA predominately recognize the fragment between 192-260 amino acids of PspA [25,26]. Based on these data the conservative fragment of PspA corresponding to this region was included into chimeric protein (Figure 1).

Fragment containing amino acids from of the A-chain of the surface protein PsaA (480-552 in the protein as shown in Figure 1) was included into chimeric protein because this fragment contains epitopes that are immunogenic and protective in mice [27].

Spr1875 fragment of amino acids from corresponding to the amino acids from 94 to 162 in the original protein contains the epitopes immunogenic in mice and devoid of presumptive immunosuppressive regions located in the $\mathrm{C}$-terminal part of the molecule was also included into chimeric protein [13]. All these fragments of $S$, pneumoniae proteins and two immunostimulatory S.typhimurium flagellin FliC $\mathrm{N}$ - and C-terminal fragments, responsible for TLR5 signaling $[28,29]$ were connected with appropriate GS-flexible bridges. The total length of PSPF is 560 amino acids (Figure 1A). 
Citation: Suvorov A, Dukhovlinov I, Leontieva G, Kramskaya T, Koroleva I, et al. (2015) Chimeric Protein PSPF, a Potential Vaccine for Prevention Streptococcus pneumoniae Infection. J Vaccines Vaccin 6: 304. doi: 10.4172/2157-7560.1000304

Page 4 of 8

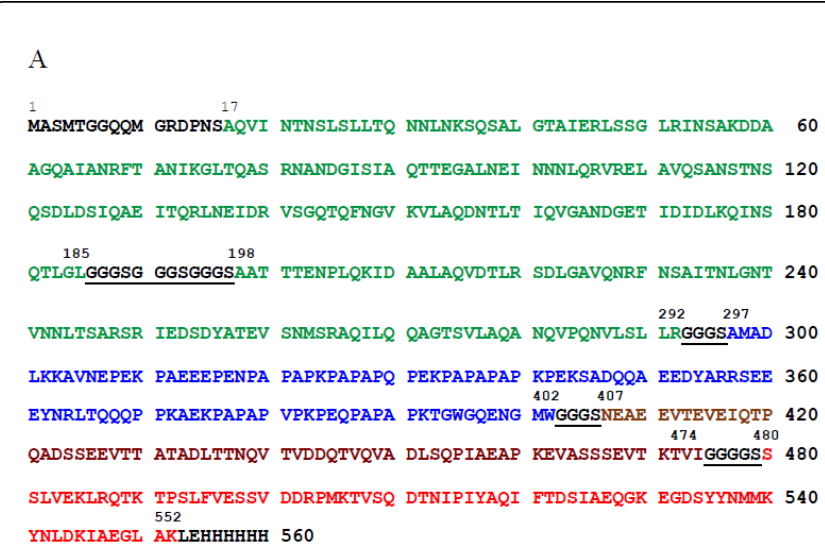

B

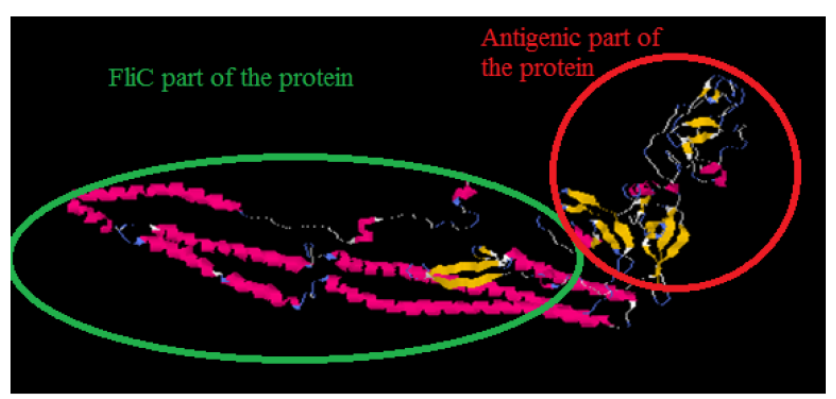

Figure 1: The sequence and structure of the chimeric protein PSPF. A) Schematic representation of the immunogenic domains in the protein molecule1-16 T7-tag (from pET24b+), 17-185 N-terminal fragment 34 of flagellin FliC (green), 186-197 GC-flexible bridge, 198-292 C-terminal fragment of flagellin FliC (green), 293-296 GCflexible bridge, 297-402 PspA (blue), 403-406 GC-flexible bridge, 407-474 Spr1875 (brown), 475-479 GC-flexible bridge, 480-552 PsaA (red), 553-560 His-tag (from pET24b+), Flexible bridges and tags are underlined, In PSP protein the amino acids 17-296 were deleted, The predicted 3D- structure of PSPF shown in $\alpha$-helixes and $\beta$-layers.

Analysis of the amino acid sequence of this protein performed with ProtParam program [30] has shown that the molecular weight of the chimeric protein is $59.3 \mathrm{kDa}, \mathrm{pI}$ is 4.71 . The predicted 3D-structure of the obtained protein vaccine (Figure 1B) shows that it contains two domains; one of them is composed of $S$. pneumoniae protein fragments and the second-of flagellin $\mathrm{N}$ - and C-termini. The structure obtained predicts that flagellin termini will have no constrains in their interaction with TLR-5.

According to NCBI Reference Sequence Database [31] the fragments of conservative surface proteins included into the PSPF were present in the majority of $S$. pneumonia strains and when applied for immunization could be protective against the most part of pneumococcal strains.

Computational analysis revealed that all parent proteins included in PSPF contain significant amounts of predicted intrinsic disorder. A multi-parametric approach for the prediction of the overall predisposition revealed that chimeric PSPF protein also possesses high degree of intrinsic disorder. Figure 2 illustrates the disorder-based "assembly" of the designed artificial protein by representing the
PONDR $^{\circ}$ VSL2-based disorder profiles of the parent FliC, PspA, Spr1875, and PsaA proteins together with the disorder propensity plot of the resulting chimeric PSPF protein. Figure 2 clearly shows that similar to the parent proteins, the hybrid PSPF protein is expected to be mostly disordered. Curiously, distributions of the disorder propensities in the FliC, PspA, Spr1875, and PsaA regions incorporated in this protein differ significantly from distribution of their disorder predispositions within the corresponding parent proteins, indicating that disorder propensity is content-dependent.

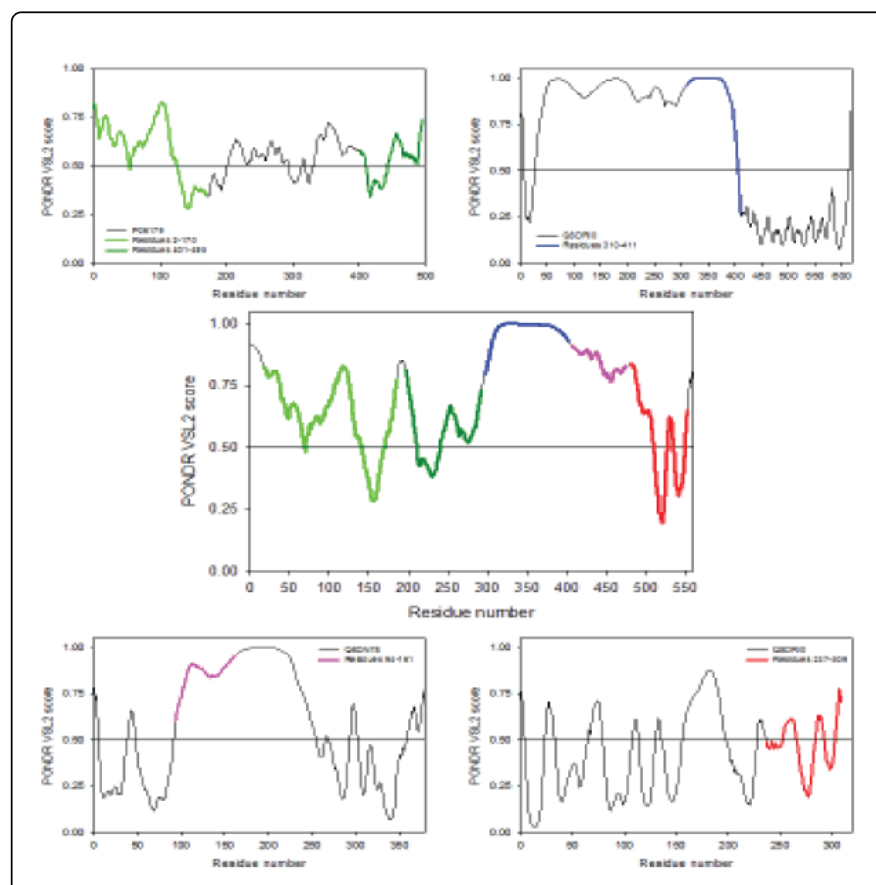

Figure 2: PONDR ${ }^{\circ}$ VSL2-based disorder profiles of the parent FliC, PspA, Spr1875, and PsaA proteins together with the disorder propensity plot of the resulting chimeric.

\section{PSPF protein}

The majority of the PONDR curves (Figure $3 \mathrm{~A}$ ) are located above the 0.5 threshold, thereby indicating that the PSPF protein is expected to be highly disordered, since scores above 0.5 are considered to correspond to the disordered residues/regions. Often, intrinsically disordered proteins and regions are involved in protein-protein interactions and molecular recognitions there are numerous reports emphasizing that these proteins are able to undergo at least partial disorder-to-order transitions upon binding, which is crucial for recognition, regulation, and signaling $[18,32]$. The results of the analysis employing ANCHOR algorithm shown in Figure 3B indicate that this protein is expected to have at least 9 disorder-based binding sites (residues 20-29, 65-73, 211-216, 260-306, 339-382, 388-459, 473-483, 514-523, and 536-547). These regions have significant potential to be binding sites for an appropriate but typically unidentified partner protein.

\section{Effect of FliC portion of the vaccine on immunogenicity}

To compare the immunogenicity of PSPF and PSP, the mice were immunized with both proteins in the doses of $20 \mu \mathrm{g} /$ mouse for prime 
Citation: Suvorov A, Dukhovlinov I, Leontieva G, Kramskaya T, Koroleva I, et al. (2015) Chimeric Protein PSPF, a Potential Vaccine for Prevention Streptococcus pneumoniae Infection. J Vaccines Vaccin 6: 304. doi: 10.4172/2157-7560.1000304

Page 5 of 8

and $10 \mu \mathrm{g} /$ mouse for boost immunizations three weeks later. Figure $4 \mathrm{~A}$ shows, that the presence of flagellin domain in PSPF increased specific antibody titers by 1.0-1.5 orders of magnitude at all the time points tested. Thus we could suppose that this effect was achieved by the immune-stimulatory activity of the flagellin domain included in PSPF.

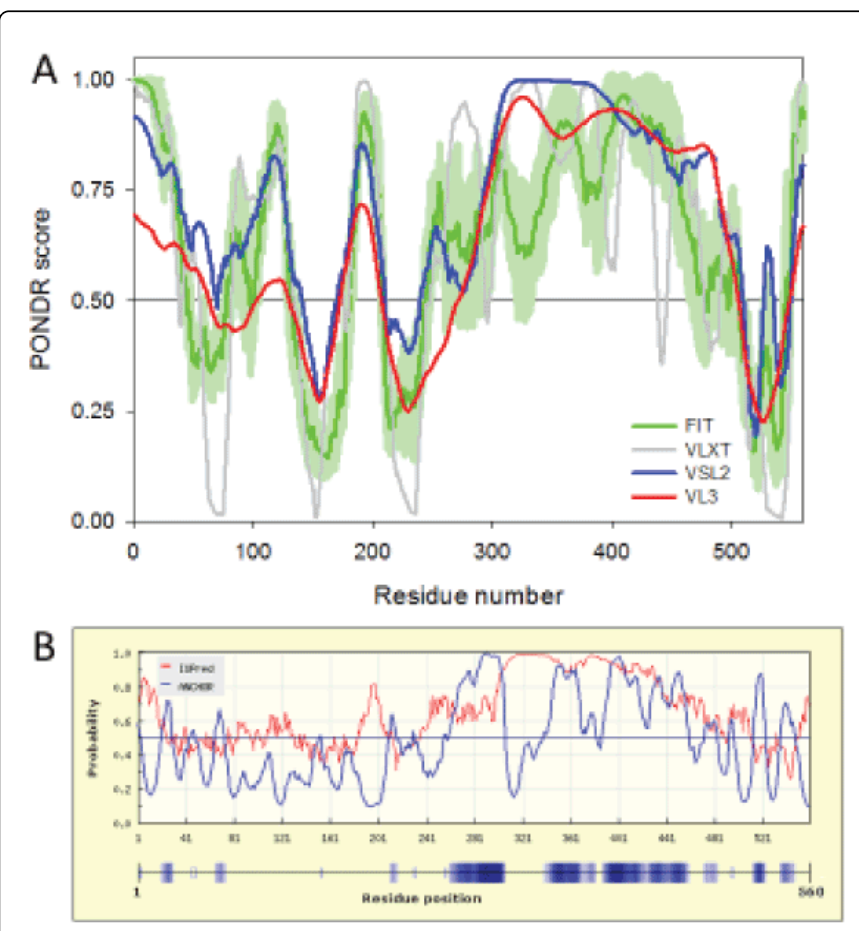

Figure 3: A) PONDR score analysis of PSPF chimeric protein, B) Analysis of PSPF employing algorithm ANCHOR.

\section{Immunogenic properties of the PSPF applied in different doses}

After the immunization, the titers of anti-PSPF antibodies in mice sera were determined by regimen indicated in Tables 2 and 3 . Stimulation of the immune response in all the experimental groups were detected on the $14^{\text {th }}$ day after the booster vaccination $\left(35^{\text {th }}\right.$ day of the experiment), but the mean dose $(10 \mu \mathrm{g} / \mathrm{mouse})$ provided a statistically significant increase of the humoral immune response level as compared with the other experimental groups. However, starting from day 42 of the vaccination, this group showed the most pronounced downward trend in the quantity of circulating antibodies and after 28 days from the second vaccination (day 49 of the experiment), the level of specific circulating antibodies in all experimental groups was virtually identical. Specific IgG continued to circulate at the same level in all the groups for the following 20 days (Figure $4 \mathrm{~B}$ ).

\section{Study of the PSPF-Driven Protective Effects}

\section{Intraperitoneal infection}

After the intraperitoneal infection, all the mice from control group (placebo) died on the second day of experiment. Death rates of immunized mice differed among the groups. The best protection was observed in the group of mice immunized with the lowest dose of the vaccine (Figure 5A). Mice vaccinated twice with recombinant vaccine stimulated the development of a specific immune response, which provided $25-40 \%$ protection against lethal intraperitoneal infection. In the group of mice immunized with the reference vaccine, the mortality rate was close to the control value- $88 \%$. Thus, the level of protection provided by the recombinant pneumococcal vaccine was higher compared to the reference vaccine.

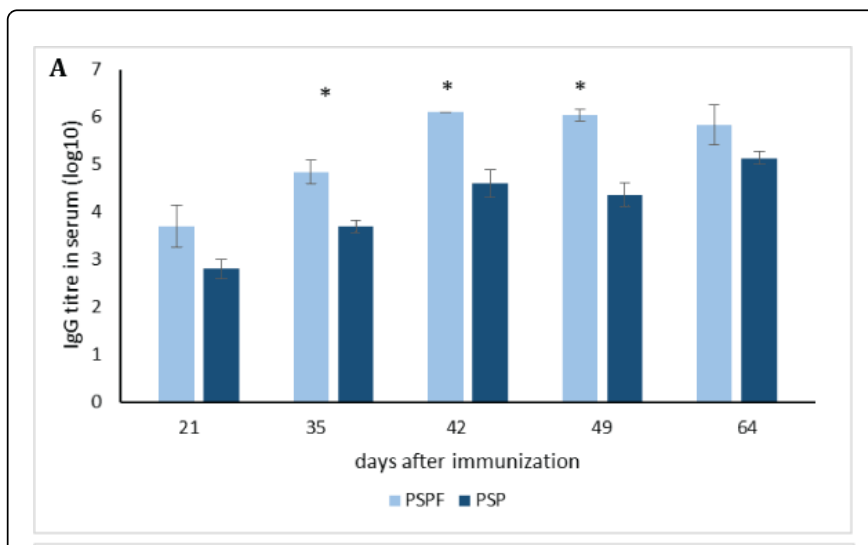

B

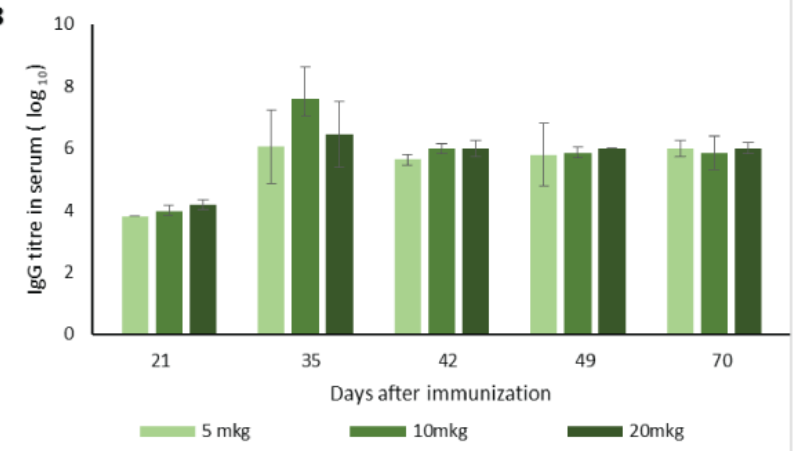

Figure 4: Immunogenicity of chimeric proteins in BALB/c mice. A) Stimulation of immune response by PSPF or PSP with or without Salmonella flagellin fragments Mice $(n=10)$ were immunized subcutaneously with the chimeric proteins PSPF and PSP in doses $20 \mu \mathrm{g}$ and three weeks later with $10 \mu \mathrm{g}$. Specific anti-PSP IgG titers on says $35,42,49$ and 70 were assessed. Results are shown as mean \pm SD. ${ }^{*}$ Differencies between the groups immunized by PSPF or PSP were statistically significant on 35,42 and 49 days after immunization. B) Immunogenicity 95 of PSPF protein in different dosage. Mice $(n=10)$ were immunized subcutaneously with the chimeric protein in doses of 5, 10 and $20 \mu \mathrm{g}$ and three weeks later with one-half of each dose (boost). Specific IgG titers on days 21 , $35,42,49$ and 70 were assessed. Results are shown as mean \pm SD.

\section{Intranasal infection}

Death of the animals after intranasal infection in control group started on the second day and on the third day in the groups immunized with PSPF. The mortality of animals immunized with PSPF was $40 \%$ after 10 days of monitoring. Death rate of animals in control group was $63 \%$ (Figure 5B). This experiment was repeated three times with different concentrations of vaccine protein. In all the cases the 
Page 6 of 8

difference was statistically significant. The protective level did not depend on the dose of the vaccine.

Thus, the PSPF immunization showed protective effect against S.pneumoniae intranasal infection.

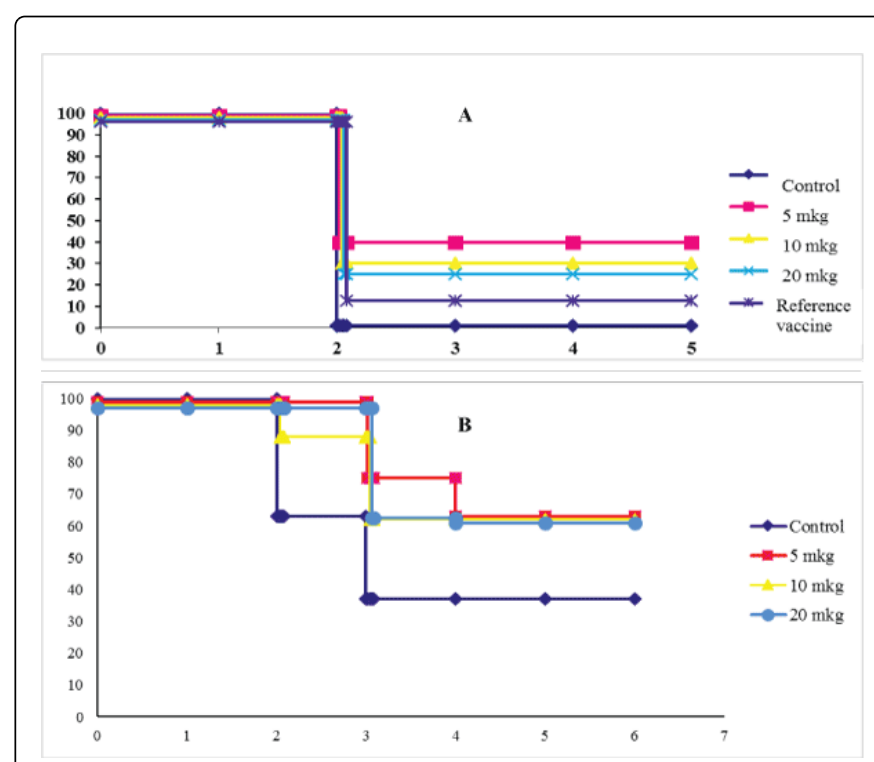

Figure 5: Surviving of animals in different groups after infection. A. Surviving of animals in different groups after peritoneal infection. The $\mathrm{X}$ axis shows the time after infection (days), on an axis $\mathrm{Y}$ survival rate of animals (\%). Infection was induced with $3 \times 102$ CFU/mouse $S$. pneumoniae strain 442 (type 19F), B) Surviving of animals in different groups after intranasal infection. The $X$ axis shows the time after infection (days), on an axis $\mathrm{Y}$ - survival rate of individuals (\%). Infection was induced with $1 \times 107 \mathrm{CFU} /$ mouse $S$. pneumoniae strain 73 (type 3). Each experimental group included 10 mice.

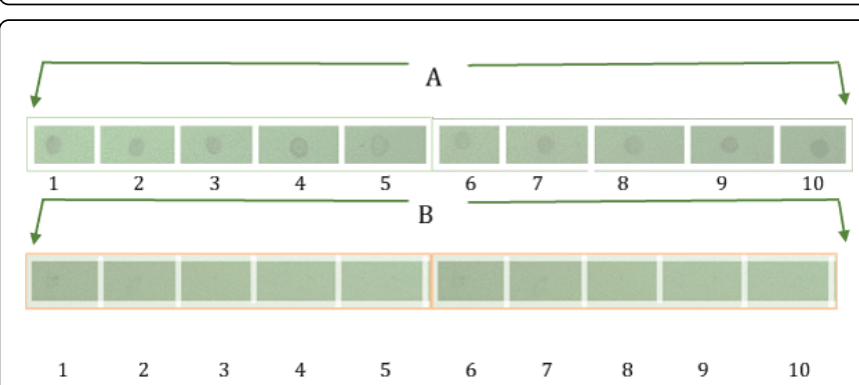

Figure 6: Dot-blotting analysis of Streptococci pneumoniae strains. A) anti-PSPF antisera; B) Control sera. $S$. pneumoniae serotypes under study: 1-6, 2-19, 3-19F, 4-6ABC, 6-9VA, 6-19A, 7-3, 8-34, 9-14, 10-9L.

\section{Dot-Blot Analysis of Streptococci pneumoniae Strains}

Interaction of PSPF-specific sera with $S$. pneumoniae strains listed in Table 1 was studied employing the dot-blot method. The sera recognized all $S$. pneumoniae strains under study belonging to different serotypes in contrast to control sera taken from nonimmunized animals (Figure 6).

\section{Discussion}

At present several vaccines against $S$. pneumoniae infections were introduced in the public health systems. FDA approved two different types of vaccines: pneumococcal conjugate vaccines and pneumococcal 23-valent polysaccharide vaccine [33]. Polysaccharide vaccines implemented on the market have been proved both efficient and safe but they have several very important disadvantages. As there are over 90 PS serotypes and serotypes distribution differs in geographical areas, it is difficult to create one universal vaccine based only on polysaccharides. Polysaccharides are T-cell independent antigens, inducing short-term immunity without immune memory. Pneumococcal conjugated vaccines due to the carrier protein CRM197 are better recognized by T-cells and induce long-lasting immunity [34]. However, though the CRM197 is over 100 times less toxic than diphtheria toxin, it still retains some toxicity, especially in high doses [35].

The above considerations advocate for development of the protein vaccines against $S$. pneumonia. Several proteins have been determined on the cell surface including PsaA, PspA, PcsB, StkP, Spr1875 and many others [36]. Many of them have been proved immunogenic and were able to induce protection against S.pneumoniae in the animal models. It is also determined that vaccines based on the epitopes from several proteins provide superior protection relatively to monovalent protein vaccines. The approach based on several epitopes in one chimeric protein allows avoiding the problem of the strains antigenic variability like in case of using PspA based vaccines, which are impeded by the high degree of genetic mozaicism and epitope variations $[24,25]$. On the other hand, implementation of the number of separate proteins and adjuvants in vaccine combination makes the vaccine a lot more difficult for standardization and it increases the cost. Major advantage of chimeric protein vaccine beside the cost effectiveness is their simplicity of production and its control, relatively high degree of conservation and $\mathrm{T}$ - dependent type of immune memory response [37-39]. These considerations resulted in construction and experimental testing of a new recombinant chimeric immunogenic protein PSPF comprising fragments of pneumococcal conservative proteins PspA, Spr1875, PsaA and flagellin domains (FliC). The molecule was analyzed in silico by several computer engines and several constructs have been generated employing DNA synthesis techniques with the following cloning and expression in the E.coli vectors. Salmonella typhimurium flagellin FliC N- and Cterminal fragments were included as "internal adjuvant" due to their ability to interact with Toll-like receptor-5 (TLR-5). Conserved N- and C- termini of flagellin cooperatively interact to generate a TLR-5 binding site and the middle highly immunogenic and pyrogenic part of the molecule can be deleted without the loss of TLR-5 stimulating activity $[28,29]$.

Including the FliC-domains in PSPF significantly increased the level of the humeral immune response relatively to PSP, which does not possess this region.

Double subcutaneous immunization of mice with PSPF induce development of immune response typical for T-dependent antigens characterized with significant booster effects after the second immunization. We were not able to see the difference after immunizing with three doses of PSPF $(20,10$ or $5 \mu \mathrm{g} /$ dose $)$ and it suggests that PSPF can be applied with less doses and provide little immunologic burden on the immunized individuals. 
The ability of the strains under study to bind PSPF-specific antibodies has been tested in vitro employing dot-blot assay. All the strains belonging to the major serotypes were able to precipitate chimeric molecule - specific IgG equally. The ability of the anti-PSPF $\operatorname{IgG}$ to react with all $S$. pneumonia strains under study reflects the broad specificity of the post vaccination immunity.

Protective features of antibodies against PSPF were studied on two $S$. pneumonia strains, expressing significant virulence in mice. It was discovered that the immunized animals were significantly better protected relatively the control group of animals and group of mice vaccinated by reference vaccine Prevnar. Protection was determined both after nasal or intraperitoneal immunization.

\section{Conclusion}

This study has shown the efficiency of new recombinant chimeric protein PSPF which included the PsaA, PspA and Spr1875 epitopes assembled in one molecule as vaccine against $S$. pneumoniae infection in a mouse model. The PSPF immunization induced specific immune response against the range of $S$. pneumoniae serotypes and dramatically decreased the mortality after intraperitoneal and intranasal infection. The PSPF immunization showed stronger immune response than chimeric protein PSP without FliC portion and better protective effect in comparison with the reference conjugated pneumococcal vaccine. Results of protection did not depend on the dosage of vaccine, which correlated with similar dynamics of IgG production. Most likely lot smaller doses of PSPF could provide the protection. Thus, the new chimeric protein PSPF can be considered a promising vaccine candidate against $S$. pneumoniae.

\section{Acknowledgments}

We thank professor P.P. and Aiden Griffin for useful remarks and language editing. This work was supported by State contract No 14.613.21.0023

\section{References}

1. http://www.who.int/ith/diseases/pneumococcal/en/.

2. WHO (2006) Pneumonia. The Forgotten Killer of Children [Internet].

3. Roush S, McIntyre L, Baldy L (2012) Manual for the Surveillance of Vaccine-Preventable Diseases.Centers for Disease Control and Prevention.

4. Feldman C, Anderson R (2012) Antibiotic resistance of pathogens causing community-acquired pneumonia. Semin Respir Crit Care Med 33: $232-243$.

5. Low DE (2013) What is the relevance of antimicrobial resistance on the outcome of community-acquired pneumonia caused by Streptococcus pneumoniae? (should macrolide monotherapy be used for mild pneumonia?). Infect Dis Clin North Am 27: 87-97.

6. Steel HC, Cockeran R, Anderson R, Feldman C (2013) Overview of community-acquired pneumonia and the role of inflammatory mechanisms in the immunopathogenesis of severe pneumococcal disease. Mediators Inflamm 2013: 490346.

7. Mirsaeidi M1, Ebrahimi G2, Allen MB3, Aliberti S4 (2014) Pneumococcal vaccine and patients with pulmonary diseases. Am J Med 127: 886 .

8. Weintraub A (2003) Immunology of bacterial polysaccharide antigens. Carbohydr Res 338: 2539-2547.

9. Berry AM, Paton JC (1996) Sequence heterogeneity of PsaA, a 37kilodalton putative adhesin essential for virulence of Streptococcus pneumoniae. Infect Immun 64: 5255-5262.
10. Hammerschmidt S, Bethe G, Remane PH, Chhatwal GS (1999) Identification of pneumococcal surface protein A as a lactoferrin-binding protein of Streptococcus pneumoniae. Infect Immun 67: 1683-1687.

11. Ren B, Szalai AJ, Thomas O, Hollingshead SK, Briles DE (2003) Both family 1 and family 2 PspA proteins can inhibit complement deposition and confer virulence to a capsular serotype 3 strain of Streptococcus pneumoniae. Infect Immun 71: 75-85.

12. Peppoloni S, Colombari B, Beninati C, Felici F, Teti G, et al. (2013) The Spr1875 protein confers resistance to the microglia-mediated killing of Streptococcus pneumoniae. Microb Pathog 59-60: 42-7.

13. Cardaci A, Papasergi S, Midiri A, Mancuso G, Domina M, et al. (2012) Protective activity of Streptococcus pneumoniae Spr1875 protein fragments identified using a phage displayed genomic library. PLoS ONE 7: e36588.

14. Akira S, Takeda K, Kaisho T (2001) Toll-like receptors: critical proteins linking innate and acquired immunity. Nat Immunol 2: 675-680.

15. Iwasaki A1, Medzhitov R (2004) Toll-like receptor control of the adaptive immune responses. Nat Immunol 5: 987-995.

16. Majumder K (1992) Ligation-free gene synthesis by PCR: synthesis and mutagenesis at multiple loci of a chimeric gene encoding OmpA signal peptide and hirudin. Gene 110: 89-94.

17. http://zhanglab.ccmb.med.umich.edu/I-TASSER/.

18. Dunker AK, Lawson JD, Brown CJ, Williams RM, Romero P, et al. (2001) Intrinsically disordered protein. J Mol Graph Model 19: 26-59.

19. Peng K, Vucetic S, Radivojac P, Brown CJ, Dunker AK, et al. (2005) Optimizing long intrinsic disorder predictors with protein evolutionary information. J Bioinform Comput Biol 3: 35-60.

20. Peng K, Radivojac P, Vucetic S, Dunker AK, Obradovic Z (2006) Lengthdependent prediction of protein intrinsic disorder. BMC Bioinformatics 7: 208

21. Xue B, Dunbrack RL, Williams RW, Dunker AK, Uversky VN (2010) PONDR-FIT: a meta-predictor of intrinsically disordered amino acids. Biochim Biophys Acta 1804: 996-1010.

22. Dosztányi Z, Mészáros B, Simon I (2009) ANCHOR: web server for predicting protein binding regions in disordered proteins. Bioinformatics 25: 2745-2746

23. Studier FW (2005) Protein production by auto-induction in high density shaking cultures. Protein Expr Purif 41: 207-234.

24. Hollingshead SK, Becker R, Briles DE (2000) Diversity of PspA: mosaic genes and evidence for past recombination in Streptococcus pneumoniae. Infect Immun 68: 5889-5900.

25. Kolberg J, Aase A, Gunnhild R, Littlejohn JE, Jedrzejas MJ (2003) Epitope mapping of pneumococcal surface protein A of strain $\mathrm{Rx} 1$ using monoclonal antibodies and molecular structure modelling. FEMS Immunology and Medical Microbiology 39: 265-273.

26. McDaniel LS, Ralph BA, McDaniel DO, Briles DE (1994) Localization of protection-eliciting epitopes on PspA of Streptococcus pneumoniae between amino acid residues 192 and 260. Microb Pathog 17: 323-337.

27. Srivastava N1, Zeiler JL, Smithson SL, Carlone GM, Ades EW, et al. (2000) Selection of an immunogenic and protective epitope of the PsaA protein of Streptococcus pneumoniae using a phage display library. Hybridoma 19: 23-31.

28. Eaves-Pyles TD, Wong HR, Odoms K, Pyles RB (2001) Salmonella flagellin-dependent proinflammatory responses are localized to the conserved amino and carboxyl regions of the protein. J Immunol 167: 7009-7016.

29. McDonald WF, Huleatt JW, Foellmer HG, Hewitt D, Tang J, et al. (2007) A West Nile virus recombinant protein vaccine that coactivates innate and adaptive immunity. J Infect Dis 195: 1607-1617.

30. http://web.expasy.org/protparam/.

31. http://www.ncbi.nlm.nih.gov/refseq/.

32. Uversky VN (2013) Intrinsic disorder-based protein interactions and their modulators. Curr Pharm Des 19: 4191-4213.

33. U.S. FDA, Pneumococcal Vaccine, Polyvalent. 
Citation: Suvorov A, Dukhovlinov I, Leontieva G, Kramskaya T, Koroleva I, et al. (2015) Chimeric Protein PSPF, a Potential Vaccine for Prevention Streptococcus pneumoniae Infection. J Vaccines Vaccin 6: 304. doi: 10.4172/2157-7560.1000304

Page 8 of 8

34. Tai S-P, Lee C-HR (2010) Meningococcal and Pneumococcal Conjugate Vaccine and Method of Using Same.

35. Kageyama T, Ohishi M, Miyamoto S, Mizushima H, Iwamoto R, et al. (2007) Diphtheria toxin mutant CRM197 possesses weak EF2-ADPribosyl activity that potentiates its anti-tumorigenic activity. J Biochem 142: 95-104.

36. Olafsdottir N.F., Lingnau K, Nagy E, Jonsdottir I (2012) Novel proteinbased pneumococcal vaccines administered with the Th1-promoting adjuvant IC31 induce protective immunity against pneumococcal disease in neonatal mice. Infect Immun 80: 461-468.

37. Miyaji EN, Vadesilho CF, Oliveira ML, Zelanis A, Briles DE, et al. (2015) Evaluation of a vaccine formulation against Streptococcus pneumoniae based on choline-binding proteins. Clin Vaccine Immunol 22: 213-220.
38. Ogunniyi AD, Grabowicz M, Briles DE, Cook J, Paton JC (2007) Development of a vaccine against invasive pneumococcal disease based on combinations of virulence proteins of Streptococcus pneumoniae. Infect Immun 75: 350-357.

39. Briles DE, Hollingshead SK, Paton JC, Ades EW, Novak L et al. (2003) Immunizations with pneumococcal surface protein $\mathrm{A}$ and pneumolysin are protective against pneumonia in a murine model of pulmonary infection with Streptococcus pneumoniae. J Infect Dis 188: 339-348. 